\title{
Social Currency: The Raconteur's Investment Portfolio
}

\author{
By Demos Vardiabasis* \\ Natalie Moshiri ${ }^{\dagger}$ \\ Yury Adamov ${ }^{t}$ \\ Samuel L. Seaman ${ }^{\circ}$
}

\begin{abstract}
"What is the most resilient parasite? Is it bacteria, a virus, an intestinal worm? It's an idea...resilient, and highly contagious. Once an idea has taken hold of the brain, it's almost impossible to eradicate." (Inception, 2010) Social media, with its free-flowing current of "ideas", has become the virtual playground for marketers determined to build communities around organizations, brands, or new products. Value is best created when firms engage customers in ways that nurture community. Experts agree that the ideal strategy for inviting customers to community is to tell a provocative story...the more compelling the story, the greater will be the odds for "inception" of the idea. Event analysis for twenty, strategic corporations in the healthcare/ wellness and fashion sectors shows a systematic relationship between key story-telling metrics, and significant increases in Twitter followers (new members of the community. A powerful observational result is that returns on social media investment are greatest when tweets focus on live or digital events, particularly those which appeal to a wide-ranging collection of communities sharing common interests, values, and aspirations.
\end{abstract}

\section{Introduction}

As social media enthusiasts become absorbed in their preferred networks, companies have followed suit, developing their own social media presence with the hope of luring many consumers to their brands. Social media applications like Twitter present new and unique opportunities for organizations to interact with customers. Whilst there is much anecdotal evidence of large scale social media adoption in business, extracting and measuring the value added from social media investments, is challenging at best. Traditionally, companies have employed social media experts, consultants, and online media coordinators to develop a strong customer

\footnotetext{
*Professor, Pepperdine University, USA.

${ }^{\dagger}$ Freelance Marketing Consultant, USA.

${ }^{\star}$ Student, Pepperdine University, USA.

Professor, Pepperdine University, USA
} 
following, yet, companies seldom realize the growth in followers needed to justify further investment in social media initiatives. Having surveyed executives across the globe, McKinsey (2009), reported that whilst 56\% of executives said they used social media to communicate with customers, over a third of them reported that they had not yet been able to measure the benefit of that investment

Value derives not from social media presence itself, but rather because of the compelling use of that platform. In addition to the usual e-commerce activities, messages in social media can be used to create virtual customer communities; communities that support relationship management, branding, and product innovation. Companies adept at engaging customers in meaningful conversation and co-creation of content, empower their customers, creating loyalty and champions of the organization. A static presence in Twitter will not insure that customers are drawn to the organization's profile to engage the firm and, possibly, other customers. Instead, organizations must become provocative raconteurs adept at telling those stories which pique the interest of, and encourage interaction amongst current and potential customers. And, they must leverage the contributions made by those participants. Culnan, M. J., McHugh, P. J., \& Zubillaga, J. I. (2010) argue that the most effective implementations in social media are those based on three elements: "mindful adoption, community building, and absorptive capacity."

\section{Why Twitter?}

Twitter is a popular blogging service, allowing users to create short messages and publish them for a worldwide audience. With an active user base of approximately 230 million (June 2014), Twitter provides an international forum for users to share various media, hold discussions on various real-time events, or simply update their status. As each user is limited to 140 characters per tweet, messages must be brief with routed links to further information or they can provide short commentary on current events. There are also opportunities to exchange comments with others, using hash tag linking. With an average of 500 million tweets going out per day, however, companies and individuals find it difficult, indeed, to create a breaking story or trend. Previous research has shown that "individuals need to forward [information] to other members, thus having to actively engage rather than passively read it and rarely act on it" (Romero, Galuba, Asur, Huberman). These authors also found that an average Twitter user re-tweets only one in 318 URLs on their Twitter feed. To reach a sizeable audience with social media, companies must acquire followers, and, keep them actively engaged in their brand (passive Twitter users provide little multiplicative properties as they are unlikely to engage the company online).

There may be several factors in establishing just how users choose to engage more proactively. Suh, B., Hong, L., Pirolli, P., \& Chi, E. H. (2010) found that URLs, hashtags, number of followers, and age of account all are highly correlated with retweetability. However, they reported that number of past tweets does not predict retweetability. This may show that in order to have 
increased influence, a company would need to provide additional information (URL links to a blog for example), and actively grow their follower base.

The matter is further complicated, when one considers the million follower fallacy (Avnit). Often followers are added either because of the size of an existing follower base or as a general courtesy when one follows another. In essence, followers are only valuable as a vehicle to push a company's brand if they are interested in the general topics covered by the company. Additionally, the type of organization tweeting can have significant influence on the effectiveness of tweeting. According to Cha, M., Haddadi, H., Benevenuto, F., \& Gummadi, P. K. (2010), news corporations would have more active users retweeting a diverse topic base, whilst celebrities or specialized accounts would only have influence in their particular focus. Large-scale influence, therefore, requires not only a large follower base but also one that provides a sense of community for followers, allowing them to feel connected and active participants in the conversation.

\section{Motivation}

In summary, traditional Twitter recommendations often focus on providing "optimal content"; companies often outsourcing the role to public relations firms. However, this may create a solitary effect, with the company missing out on cross-promotions available through the various participatory events (live, digital, product launch, or promotional). We would argue that, in order to build a strong sense of community and thereby engage an active user base, there ought to be a "communal focus" in posted tweets...especially, during live events, whether the company is an active sponsor of the event, or the focus relates to an event discussed on Twitter live. This focus and form of interaction allows for self-selection amongst potential followers. In this paper, we address the importance of developing a sense of community amongst Twitter followers, and we highlight the positive consequence of leveraging the company's social media investments rather than treating social media as an isolated company experiment. More importantly, perhaps, we investigate the association (value added), if any, between commonly used social media metrics and a critical performance indicator - new followers.

\section{Our Data}

In order to test the importance of story-telling in general and event-based tweeting, specifically, we have analyzed the Twitter activities of 20 major corporations in the health/wellness and fashion sectors; 10 from the fashion industry (BCBG, Burberry, Chanel, Diesel, Gucci, Helmutlang, Lanvin, Rag Bone, Ralph Lauren, Zara) and 10 from health \& wellness (24 Hour Fitness, Beach Body, Body Media, Fitbit, GNC, Gold's Gym, MyFitnessPal, Nike Fuel, Weight Watchers, Yoga Works). These two industries have been chosen because they already have a strong sense of community and associated events should be particularly important to new followers. We mapped each of these 
Twitter accounts from 10/4/2013 to 6/9/2014 (using www.TwitterCounter. com) to identify follower spike days. A "spike" is defined as any large percentage addition in number of followers. There were a total of 99 spike days, calculated by comparing day over day changes in new followers. These changes were divided by average new followers on 6/13/2014 to standardize percentages of growth for all companies selected. We have also randomly sampled 76 nonspike days characterized by small percentage growth in number of followers, calculated in identical fashion for the same companies. The entire Twitter feed for all companies selected over this period has been gathered as well (using www.allmytweets.net). Aggregating the tweets we have tracked each instance of a retweet, hashtag or Twitter name mentioned in the previous 48 hours of the spike or random day chosen. And finally, we have recorded any events mentioned, refining and creating the following categories: Live, Digital, Promotional, Product, and Celebrity.

\section{Results}

We have analyzed many of the usual metrics for social media - retweets, hashtags, embedded URLs, photo or link attachments, and Twitter mentions. Whilst basic numbers like these, provide an indication of whether or not followers seem to appreciate the content, they don't necessarily capture audience sentiment; specifically, which aspects of the content perform best, in the sense that they lead to increased followers and improved brand loyalty. Our analysis is rather unique, then, as we have studied all significant spikes (significant increase) in number of followers for the companies mentioned above (again, a spike has been defined as an increase in followers of more than $100 \%$ over the previous number of followers added per day). Additonally, we have created a number of new "event-based metrics" related to the occurrence of live events, digital events, promotional events, and celebrity. A complete list of the independent variables used along with their definitions, and results of a comprehensive logistic regression analysis of the binary outcome variable (spike or no spike), can be found in Tables 1 and 2, respectively.

Table 1. Variable Definitions

\begin{tabular}{|ll|}
\hline Variable Definition \\
\hline RT & \# of retweets in the dates covered for that selected spike/non-spike \\
\hline Person & $\begin{array}{l}\text { \# of people tweeted @ in the dates covered for that selected spike/non-spike } \\
\text { event. }\end{array}$ \\
\hline Hashtag & $\begin{array}{l}\text { \# of hashtages in tweets in the dates covered for that selected spike/ non- } \\
\text { spike event. }\end{array}$ \\
\hline Live & Yes/No indicator of a live event tweeted during selected time period \\
\hline Digital & Yes/No indicator of a digital event tweeted during selected time period \\
\hline Promotion & Yes/No indicator of a promotional event tweeted during selected time period \\
\hline Product & $\begin{array}{l}\text { Yes/No indicator of a product launch event tweeted during selected time } \\
\text { period }\end{array}$ \\
\hline Celebrity & Yes/No indicator if a celebrity tweeted during selected time period \\
\hline
\end{tabular}


Table 2. Logit Analysis (Full Model)

\begin{tabular}{|lllll|}
\hline Coefficient & B & S.E. & Sig. & $\operatorname{Exp}(\mathrm{B})$ \\
\hline RT & .271 & .218 & .214 & 1.312 \\
\hline Person & .027 & .026 & .301 & 1.027 \\
\hline Hashtag & -.043 & .033 & .199 & .958 \\
\hline Live** $^{* *}$ & .961 & .460 & .037 & 2.614 \\
\hline Digital*** & 2.246 & .528 & .000 & 9.451 \\
\hline Promotion** & 1.330 & .648 & .040 & 3.782 \\
\hline New Product*** & 1.966 & .467 & .000 & 7.142 \\
\hline Celebrity & .471 & .608 & .439 & 1.601 \\
\hline Constant & -1.623 & .330 & .000 & .197 \\
\hline
\end{tabular}

Overall Probability of Correct Classification $=.81$

Nagelkerke R Square $=.478$

$* *$ indicates significance at .05

*** indicates significance at .01

The results are a bit surprising. Firstly, we have found that retweets, hashtags, Twitter mentions, links, and embedded URLs or photos, are not significantly associated with spikes in number of followers. In fact, the only variables significantly associated with spikes in followers, for the companies investigated, are those related to events. Estimated odds ratios for all significant variables provide important insights. For example, the odds of a significant spike in followers following any live event are about 2.6 times the odds of a spike in followers given that there was no live event. Similarly, the odds of a spike in followers after a digital event are nearly 10 times the odds of a spike given no event. If an organization uses Twitter to publicize a promotional event, the odds are quite good that there will be a spike in followers (3.8). And finally, when Twitter is used to create community around a new product launch, the odds of a substantial increase in followers is again, quite large (about 7).

\section{Conclusions}

Story-telling is indeed an essential tool for creating social currency; how you tell the story is equally important. Results of our study demonstrate that the most effective story telling (i.e. stories that connect with customers on an emotional level and create front-of-mind recall amongst followers) almost always involve the active participation of raconteurs (whether specialists from the organization or highly engaged customers) telling stories about events that have meaning for existing and potential customers. This is especially true of live, digital, and promotional events that appeal to the collective interests of distinct yet convergent communities. 


\section{References}

Cha, M., Haddadi, H., Benevenuto, F., \& Gummadi, P. K. (2010). Measuring User Influence in Twitter: The Million Follower Fallacy. ICWSM, 10, 10-17.

Culnan, M. J., McHugh, P. J., \& Zubillaga, J. I. (2010). How Large U.S. Companies Can Use Twitter And Other Social Media To Gain Business Value. MIS Quarterly Executive, 9(4), 243-259.

McKinsey Quarterly, September 2009, available at http://www.mckinseyquarter ly.com/home.aspx.

Romero, D. M., Galuba, W., Asur, S., \& Huberman, B. A. (2011). Influence and passivity in social media. In Machine learning and knowledge discovery in databases (pp. 18-33). Springer Berlin Heidelberg.

Suh, B., Hong, L., Pirolli, P., \& Chi, E. H. (2010, August). Want to be retweeted? large scale analytics on factors impacting retweet in twitter network. In Social computing (socialcom), 2010 ieee second international conference on(pp. 177184). IEEE. 